\title{
Early clip-with-line method for colorectal endoscopic submucosal dissection
}

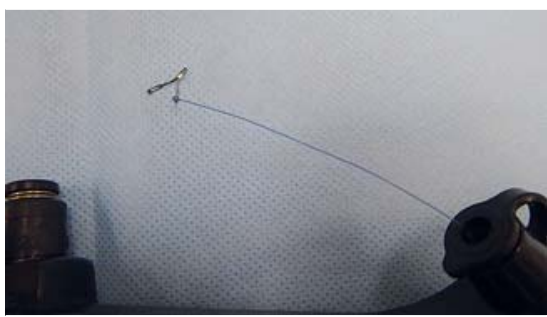

- Fig. 1 The end of the line coming out of the accessory channel was tied to a Zeoclip.

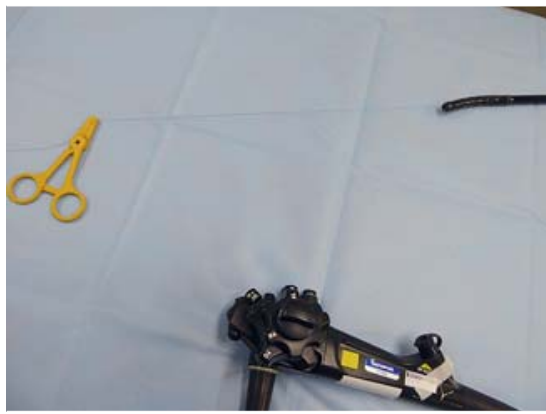

Fig. 2 The Zeoclip was fixed on the scope with tape. The other end of the line was grasped with light Pean forceps.

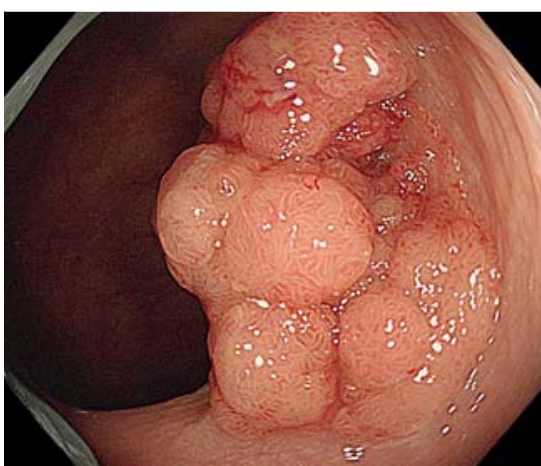

Fig. 3 Colonoscopy showed a large granular laterally spreading tumor (LST-G, $30 \mathrm{~mm}$ ) in the transverse colon.

Colorectal endoscopic submucosal dissection (ESD) is a widely accepted procedure but involves technical difficulties and a high risk of perforation [1]. To overcome these problems, several methods for exerting traction have been reported. Most of these methods start after the
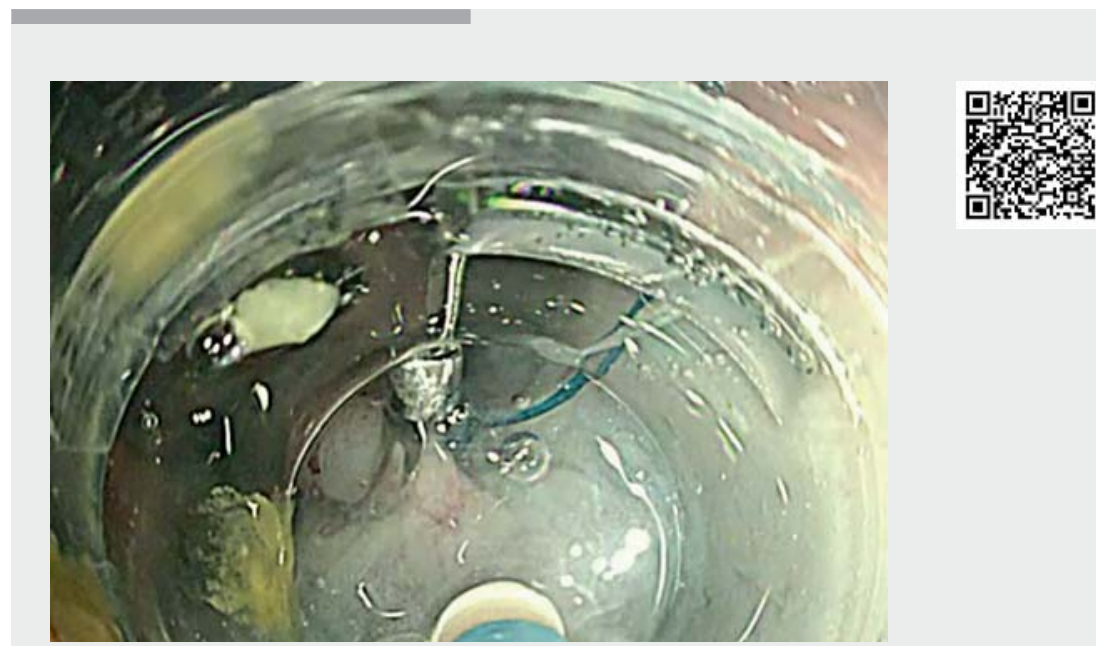

Video 1 This clip-with-line is a new traction method that facilitated good visualization and countertraction at the stage of the mucosal incision.

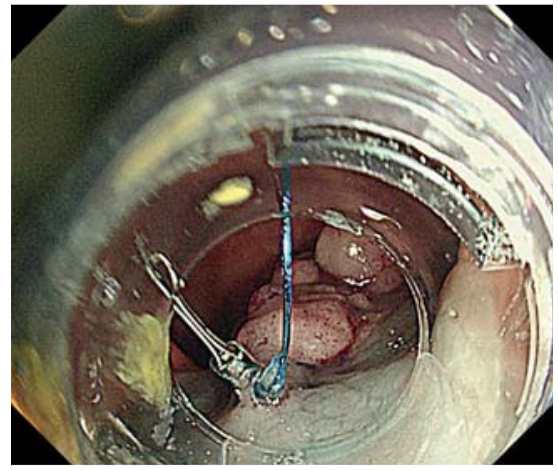

-Fig. 4 The Zeoclip-with-line grasped the injected area next to the anal edge of the lesion before the mucosal incision was started.

creation of the mucosal flap, which is time-consuming [2,3]. To obtain good visualization at the stage of the mucosal incision, we developed an early clip-withline $(E C L)$ method. Traction by this method was started immediately after the injection of hyaluronic acid solution into the submucosal layer.

Before the ESD procedure was started, the following preparations were made. First, a long nylon line was inserted into the accessory channel of the scope using

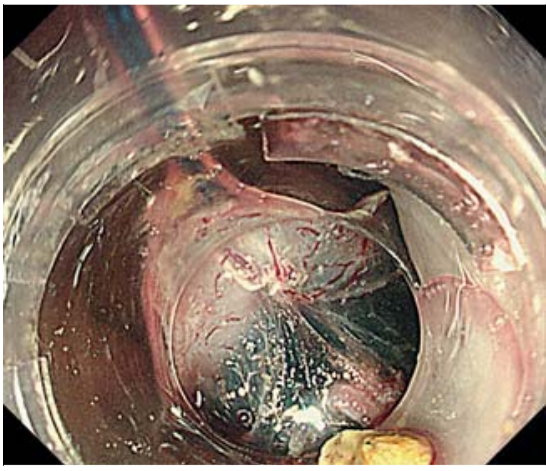

$>$ Fig. 5 It was easy to obtain good visualization and countertraction at the stage of the mucosal incision.

biopsy forceps (FB-24Q-1; Olympus, Tokyo, Japan) ( $\downarrow$ Video 1$)$. The end of the line coming out of the accessory channel was tied to a Zeoclip (ZP-CH; Zeon Medical, Tokyo, Japan) (\Fig. 1). The Zeoclip was fixed to the scope with tape. The other end of the line was grasped with light Pean forceps ( $\triangleright$ Fig. 2). Next, the scope (PCF-H290TI or GIF-Q260]; Olympus) was inserted ( $\triangleright$ Fig.3). Hyaluronic acid solution (Mucoup; Johnson and Johnson, Tokyo, Japan) was then injected 
into the submucosal layer on the anal side of the lesion. The tape fixing the Zeoclip was removed, and a Zeoclip delivery catheter (ZP-S-165S; Zeon Medical) attaching the Zeoclip with the line was inserted into the accessory channel ( $\triangleright$ Video 1 ). The Zeoclip grasped the injected area of mucosa next to the anal edge of the lesion and the line was gently pulled ( $\triangleright$ Fig. 4 ,

- Fig.5). The mucosal incision was then started from the area next to the anal side of the Zeoclip ( $\triangleright$ Video 1 ). This resulted in good visualization and countertraction at the stage of the mucosal incision.

The ECL method is a novel procedure that may overcome the difficulty of colorectal ESD.

Endoscopy_UCTN_Code_TTT_1AQ_2AD

\section{Competing interests}

The authors declare that they have no conflict of interest.
The authors

Hideyuki Takashiro, Hirofumi Saito, Shinichi Tazawa, Masatoshi Usui, Katsunobu Tawada, Hiromasa Nomoto, Kazuhiko Kita

Department of Gastroenterology, Chiba Kaihin Municipal Hospital, 3-31-1 Isobe, Mihama-ku, Chiba, Japan

\section{Corresponding author}

\section{Hideyuki Takashiro, MD}

Chiba Municipal Kaihin Hospital, 3-31-1

Isobe, Mihama-ku, Chiba, Japan

Fax: +81-43-278-7482

htakashiro84@gmail.com

\section{References}

[1] Hayashi N, Tanaka S, Nishiyama S et al. Predictors of incomplete resection and perforation associated with endoscopic submucosal dissection for colorectal tumors. Gastrointest Endosc 2014; 79: 427-435

[2] Ritsuno H, Sakamoto N, Osada T et al. Prospective clinical trial of traction device-assisted endoscopic submucosal dissection of large superficial colorectal tumors using the S-O clip. Surg Endosc 2014; 28: 3143-3149

[3] Yamasaki Y, Takeuchi Y, Uedo N et al. Efficacy of traction-assisted colorectal endoscopic submucosal dissection using a clipand-thread technique: a prospective randomized study. Dig Endosc 2018; 30: 467476
Bibliography

DOI https://doi.org/10.1055/a-1090-7096

Published online: 29.1.2020

Endoscopy 2020; 52: E265-E266

(c) Georg Thieme Verlag KG

Stuttgart · New York

ISSN 0013-726X

\section{ENDOSCOPY E-VIDEOS}

https://eref.thieme.de/e-videos

口回 Endoscopy E-Videos is a free access online section, reporting 回: on interesting cases and new techniques in gastroenterological endoscopy. All papers include a high quality video and all contributions are freely accessible online.

This section has its own submission website at https://mc.manuscriptcentral.com/e-videos 